\title{
MA Defence: "The Turn to Practice in Medicine: Towards Situated Drug Safety"
}

\author{
by David Peddie
}

\begin{abstract}
Vu Thuy Anh Phan
School of Communication

Simon Fraser University

Our dear colleague, David Peddie, will defend his MA Thesis on Thursday, March 31, 2016 at Harbour Centre, Room 2245(10:30 am - 12:30 pm). Here is the abstract of his thesis "The Turn to Practice in Medicine":
\end{abstract}

\begin{abstract}
:
Research in medicine is often undertaken with the aim to produce abstract knowledge. This thesis is concerned with how this aim relates to the on-the-ground practice of medicine and the influence that conceptualizations of care have on the ways that we do research, identify problems, and design and implement solutions. Following the work of scholars in science and technology studies, I outline and argue for the turn to practice, an approach to research that takes an interest in "situated action" and knowledge as practiced (Suchman, $1987 / 2007)$. Drawing on an action research intervention in clinical care related to medications, I demonstrate how practice-oriented research can be done in medicine. I contrast mechanistic conceptualizations of care with ethnographic accounts, showing how drug safety proceeds through the situated and local activities of providers, and that improvement initiatives might be reappraised to enable rather than constrain or interrupt this work.
\end{abstract}

Keywords: sociomaterial; practice; situated; ethnography; medicine; drug safety 